\title{
Subsidence and Sea-Level Rise in Southeast Louisiana: Implications for Coastal Management and Restoration
}

\section{The impact of subsidence and relative sea-level change are the most critical environmental and cultural issues facing southeastern Louisiana.}

The Mississippi River delta plain is subject to the highest rate of relative sea-level rise $(3 \mathrm{ft}$ per century) of any region in the Nation largely due to rapid geologic subsidence (figure 1). Subsidence impacts the socio-economic infrastructure of southeastern Louisiana placing the communities and infrastructure at risk of being inundated by the rising sea. Compounding the subsidence problem is the forecast that the world's oceans will rise over the next century due to global atmospheric warming. Together the rising sea and subsidence accelerate coastal erosion and wetland loss, increase flooding, and increase the extent and frequency of severe storm impacts.

To assess the impact of marine transgression caused by subsidence and sea-level rise at a given location, it is necessary to have a thorough understanding of the natural processes that operate on the delta plain. Reliable scientific data are needed to identify the 'hot spots' of subsidence, where infrastructure is most at risk, and what are the best strategies to sustain and restore Louisiana's coastal wetlands. In this collaborative study, the US Geological Survey (USGS), US Army Corps of Engineers (USACE), and University of New Orleans (UNO) are responsible for developing an objective and reliable scientific database on subsidence and sea-level rise for manag-

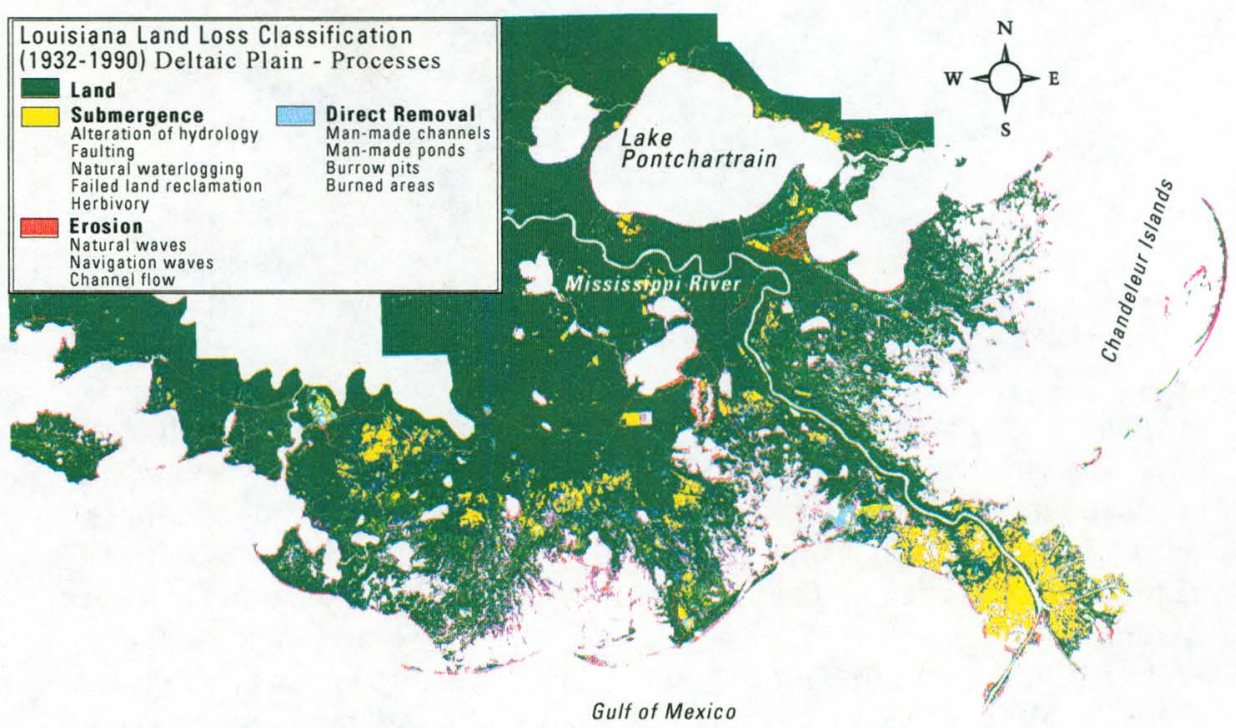

Figure 1. Map of Louisiana showing areas of submergence, erosion, and direct removal.

searchers by conducting detailed studies within the Mississippi River delta plain.

\section{Short- and Long-Term Trends}

Short-term rates of submergence are monitored using tide gauges located across southeastern Louisiana. These gauges, which have been in place since the 1930's, provide records of sea-level change. Tidegauge records document sub-decadal rises in sea level, this data combined with land-loss data provide information on how sea level affects coastal wetlands and coastal infrastructure. Long-term rates of submergence (over the past several thousand years) can be determined through radiocarbon age dating of peat deposits. Radiocarbon analysis of buried peat deposits formed at sea level will provide information on rates of subsidence and provide insight into Holocene sea-level history.

\section{Geologic Processes and Controls}

Understanding the effects of regional subsidence requires knowledge of a number of factors. Field investigations have been designed to assess subsidence at various spatial and temporal scales across the different geologic provinces of the delta plain:

- Structure: The delta plain is traversed by hundreds of coast-parallel normal growth faults. Fault traces and rates of movement can be estimated from existing databases to identify the areas where fault activation contributes to subsidence.

- Mississippi River Deposits: Much of the delta plain is located over a paleo-valley cut by the Mississippi River when sea level was lower. This incised valley was filled with deltaic deposits that range in thickness from 20 to $120 \mathrm{~m}$ (figure 2). Deltaic deposits comprise a complex network of depositional environments including sandy channel fills, silty natural lev- 
THICKNESS OF HOLOCENE SEDIMENTS, MISSISSIPPI DELTA

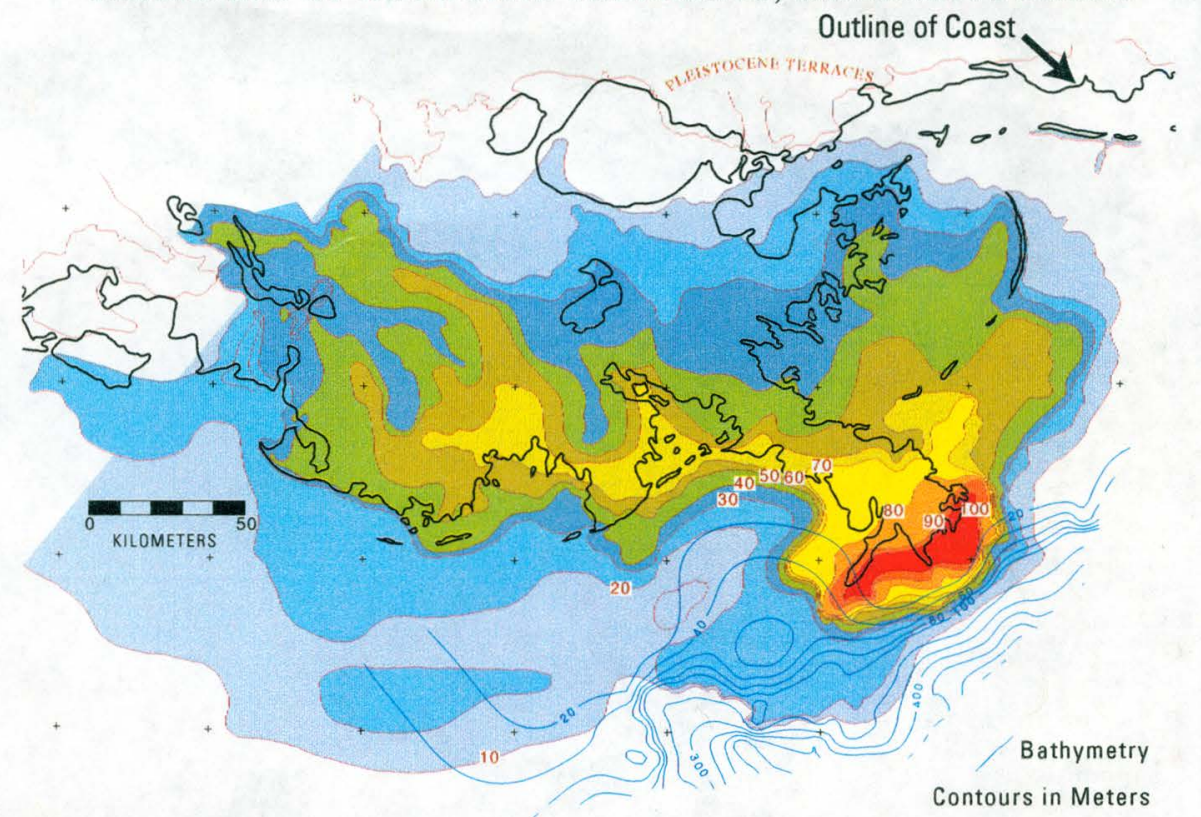

Figure 2. Map showing thickness of Holocene sediments that have constructed the modern Mississippi River Delta. Colors indicate thickness of sediments.

ees, and muddy interdistributary bays. The physical property thickness, and lateral extent, of each environment influence the rate of sediment compaction and subsidence.

- Fluid Withdrawal: At a local scale the effect of fluid withdrawal can affect subsidence. It is well documented that forced drainage areas experience enhanced subsidence (figure 3 ).

\section{Impacts of Subsidence and Sea-Level Rise}

The effect of subsidence on coastal environments of Louisiana varies from direct lowering of roads and levees to rapid degradation of marsh vegetation and soils. As the

Figure 3. Impact of fluid withdrawal along the lower Neches River Valley, changes in wetlands to open water between 1956 - 1978, including aerial photograph from 1978.

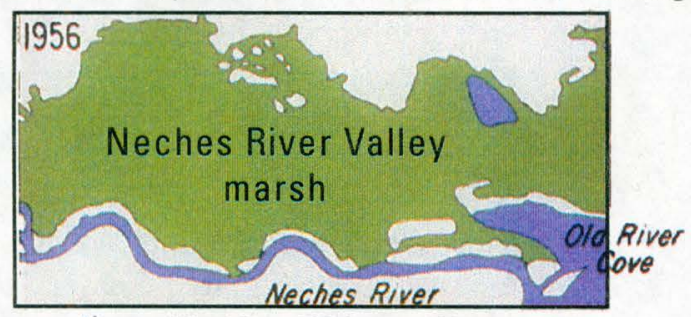

$N$ modified from White and Morton, 1997

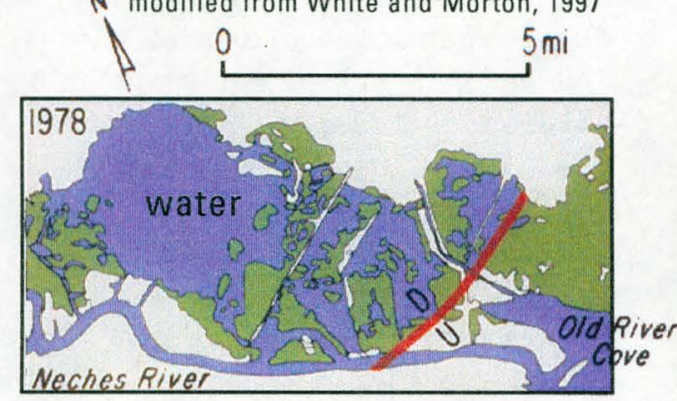

land subsides and sea level rises, the threat of flooding wetlands and commercial and residential infrastructure increases.

\section{- Coastal Marshes and Land Loss:}

Published reports indicate that coastal marshes can typically accrete at a rate that keeps pace with a slow rate of sea-level rise. As the rate of sea-level rise increases, coastal mashes cannot maintain their elevation, and they submerge and are transformed to open water. Some Louisiana marshes cope with today's conditions, future increased sea-level rise may approach or cross this critical threshold.

- Human Effects on the Coastal Wetland Environment: Since the arrival of the first settlers, mankind has been changing the Mississippi River delta plain. Variations in subsidence of the delta plain are frequently compounded by drainage of wetlands for agricultural, residential, or industrial development. Drainage causes additional subsidence of soils and reduces elevations to below current sea level in many areas. Levees are necessary to protect the developed areas from flooding. The roads and railways that cross Louisiana coastal wetlands and provide access to coastal communities and inshore and industrial facilities are being progressively lowered by subsidence and threatened by increases in sea level.

\section{Risk Assessment}

Current pressures for balanced land and water management and concerns about recovery from natural disasters and protection of environmental quality demand a new role for scientific information. Interdisciplinary research and information derived from earth, life, and social science data can contribute to both policy analysis and decision making. However, there are often no clear and unequivocal answers to landuse and environmental issues, owing both to the uncertainties inherent in the scientific information and the need to consider economic, political, social, and aesthetic values. Most scientific information is not in a form readily usable by non-scientists. Applications require adapting scientific information to a decision-oriented framework. An objective of this study is to provide the necessary components of an integrated assessment of southeastern Louisiana these are: (1) identify physical processes; (2) develop a map-based linkage of the human-physical environmental interface; (3) develop a conceptual model for decision making that recognizes uncertainty; and (4) develop a management model that incorporates an estimation of the net benefits to society.

\section{For further information, please contact:}

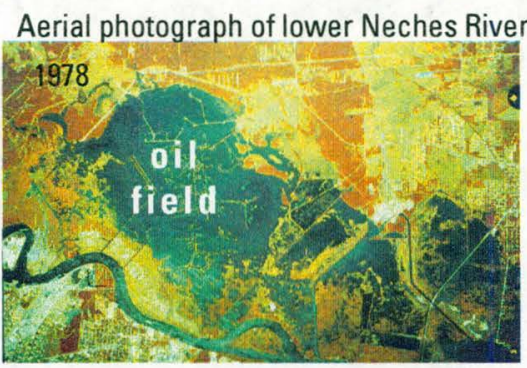

Jack L. Kindinger

U.S. Geological Survey

600 4th Street South

St. Petersburg, FL 33701

Tel.: (727) 803-8747 x3018

Fax: (727) 803-2032

Email: jkindinger@usgs.gov 